\title{
Article \\ Problem Solving and Digital Transformation: Acquiring Skills through Pretend Play in Kindergarten
}

\author{
Lena Hollenstein *D, Stefanie Thurnheer and Franziska Vogt $(D$
}

check for

updates

Citation: Hollenstein, L.; Thurnheer,

S.; Vogt, F. Problem Solving and Digital Transformation: Acquiring Skills through Pretend Play in Kindergarten. Educ. Sci. 2022, 12, 92. https://doi.org/10.3390/educsci 12020092

Academic Editors: Beth L. MacDonald, Kristin A. Searle and Colby Tofel-Grehl

Received: 10 December 2021

Accepted: 25 January 2022

Published: 28 January 2022

Publisher's Note: MDPI stays neutral with regard to jurisdictional claims in published maps and institutional affiliations.

Copyright: () 2022 by the authors. Licensee MDPI, Basel, Switzerland. This article is an open access article distributed under the terms and conditions of the Creative Commons Attribution (CC BY) license (https:// creativecommons.org/licenses/by/ $4.0 /)$.

\begin{abstract}
Institute of Research into Teaching and Learning, St. Gallen University of Teacher Education, 9000 St. Gallen, Switzerland; stefanie.thurnheer@phsg.ch (S.T.); franziska.vogt@phsg.ch (F.V.)

* Correspondence: lena.hollenstein@phsg.ch
\end{abstract}

\begin{abstract}
One of the crucial 21st-century digital skills, in the context of digital transformation, is problem solving-equally so in the fields of science, technology, engineering, and mathematics (STEM). In the context of kindergarten, learning through play is central; therefore, pretend play, and particularly guided pretend play, is suggested as an innovative way to foster skills for digital problem solving. As yet, the potential of pretend play for children's learning about digital transformation and digital problem-solving processes has hardly been researched. The paper examines how children solve digital problems in guided pretend play. In an explorative intervention study "We play the future", an information technology center (IT center) is introduced as one of the play corners for pretend play in kindergartens, together with other inputs such as a smart home corner (Internet of Things) or autonomous vehicles. Children's play was video recorded. From the 15 participating kindergartens, $13 \mathrm{~h}$ of sequences involving the IT center were analyzed using content analysis. The findings indicate that children identify problems in a play situation and solve them using problemsolving strategies, such as devising new applications and installing software. Furthermore, the findings show that the kindergarten teacher's participation in the pretend play is important for enabling longer and more complex problem-solving processes. Consequences for further teacher training to foster problem-solving skills during guided pretend play are discussed.
\end{abstract}

Keywords: digital education; digital transformation; early childhood; preschool; problem solving; STEM

\section{Introduction}

In our technology-based society, science, technology, engineering, and mathematics (STEM) are central. These disciplines have been combined as an area of interest for scientific careers, and the expression "STEM" has been coined [1]. STEM topics have been increasingly recognized as appropriate and relevant for early childhood education [2,3]. Whereas science and mathematics are often focused on in early childhood education, technology and engineering receive less attention. They are referred to as "the missing $\mathrm{T} \& \mathrm{E}$ " in early childhood STEM [3] (p. 16). Technology—digital technology in particular—will become increasingly important in the future. Digital information and communication technologies influence the ways in which we inform ourselves, communicate and interact, produce, and consume. Digital transformation thus affects almost all areas of our daily lives and work [4,5]. Digital transformation refers to the changes in structuring processes anew, which is made possible through digitalization and technology, thus bringing people, data, and technology together in new ways [6,7]. In the last two decades in particular, rapid technological progress has occurred, also influencing the further development of digital information and communication technologies [5,8]. In light of digital transformation, it is vital to identify what and how children need to learn in order to navigate the digitalized world and use digital technology, as well as be equipped with the necessary skills to develop digital technologies and shape digital transformation [5,9]. In order to be able 
to participate in the future, children need to acquire certain skills, which are referred to as "21st-century skills" [10]. This term covers a range of skills: In addition to technical skills and information management, skills such as communication, collaboration, creativity, critical thinking, and problem solving are equally crucial 21st-century skills. These skills should and can be fostered early on [2,4]. These skills, with the exception of technical skills and information management, can also be referred to as soft skills [11]. In order to deal successfully with the rapid change of digital transformation, soft skills such as communication, collaboration, critical thinking, and problem solving are required. Problem solving can be seen as a particularly important soft skill for digital transformation [11] and is an important skill in STEM in general [12,13], as well as for digital technology [10,14].

\subsection{Problem Solving and Digital Technology}

Problem solving involves deliberate cognitive reasoning [15-18]. "Problem solving begins with recognizing that a problem situation exists and establishing an understanding of the nature of the situation. It requires the solver to identify the specific problem(s) to be solved and to plan and carry out a solution, along with monitoring and evaluating progress throughout the activity" [16] (p. 123).

When combining problem solving with digitalization, there are two possibilities for problem solving [5]: (1) using digital media to learn problem solving and then solve problems, or (2) knowing, understanding, and applying functionalities and basic principles of the digital world to the problem solution. Knowing, understanding, and applying functionalities and basic principles of the digital world means understanding the processes behind the use of digital technologies. For example, children should be able to recognize algorithmic structures and to plan, formulate, and apply a structured algorithmic sequence to solve a problem $[19,20]$. The two possibilities of problem solving are not limited to a certain domain or academic subject [5]. Computational thinking is required to solve problems related to digital technology. Computational thinking can be conceptualized as a specific method of problem analysis and problem solving [21], whereby a problem is represented and decomposed in terms of algorithms and abstractions and then solutions are developed that allow for an automated process to solve the problem [22,23].

A variety of types of problems can be distinguished [24,25]. In the context of digital technology, three main types of problem solving have to be dealt with: (1) design problems, (2) diagnosis problems, and (3) debugging problems. A design problem is an ill-structured problem with a vague goal statement that only provides an indication of how a solution might be judged as better than other viable options. A diagnosis problem requires the selection and evaluation of treatment options. The outcome, however, is defined. A debugging problem means an ill-structured problem where the identification of fault(s) is the focus. Debugging means fixing a bug, for example, in software [26].

A variety of theories seek to model the process of problem solving, distinguishing different phases [12]. The present paper follows the model of Betsch et al. [15], which is close to the above OECD [16] definition. The model suggests five phases [15,16]: First, the problem must be recognized and identified (phase 1). Second, the actual situation and the goal need to be analyzed (phase 2). After that, it is possible to create a plan for solving the problem (phase 3), and execute the plan and monitor (phase 4). In the last step, the results must be evaluated (phase 5). The evaluation may lead to re-identifying the problem. Figure 1 shows the process of problem solving. 


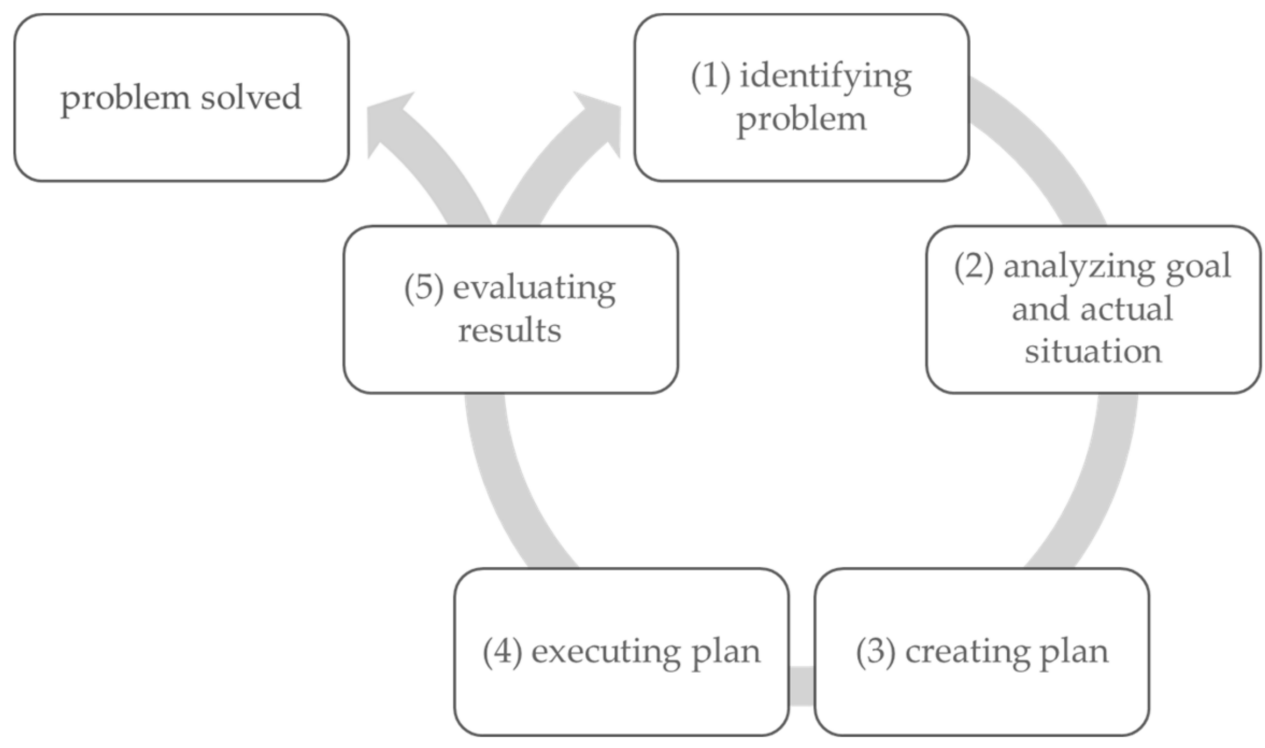

Figure 1. Process of problem solving adapted Betsch et al. [15] and OECD [16].

In problem solving, various strategies are required. Future generations will be confronted not only with gains through digitalization, but also with challenges and problems [13]. In order to deal with these challenges, it is important to learn to apply different digital strategies of problem solving within new situations, where no predefined strategy is as yet known (for example, how to modify or adapt software, or how to program specific functions on a robot). In such situations, children need to be able to think flexibly and creatively about how to overcome obstacles in the process of finding a solution. Consequently, ill-structured problems are becoming ever more relevant [13]. In relation to the aforementioned 21st-century skills for problem solving in a digital technology context, it is clear that digital technology education needs to be multifaceted. Digital education cannot be confined to using a tablet or other devices. It means, for example, "helping children gain technology literacy or teaching them that technology is used to expand our knowledge beyond what our senses can tell us, and to reflect on and share what we find out" [3] (p. 16). Less is known about how children can learn such flexible and undefined digital strategies to solve ill-structured problems and reason on how digital processes function, as well as how they can be supported during the learning process $[27,28]$.

Preschool children can imagine problem-solving strategies without solving the problem in real life; they have been found to use science-relevant concepts to solve problems set by researchers (e.g., to determine which one of two bags holds pillows, rather than rocks) [2]. Young children have positive attitudes to programming, as they learn programming embedded in social interactions [29]. These findings point to the potential of pretend play for digital education, as it relies on imagination and is embedded in social interactions.

\section{2. (Guided) Pretend Play to Promote Problem-Solving Skills in Digital Technology}

Pretend play is seen as an important way to encourage learning processes in early childhood and promote problem-solving skills [30,31] and scientific thinking [32-34]. Young children's play is a legitimate form of scientific thinking [34-36]. Following Fridman et al. [37], play-based, open-ended exploration sparks children's inquisitiveness and fosters their metacognition and self-regulation abilities. Pretend play can also help to cope with frustration [38]. All these aspects are relevant to a problem-solving process. Exploring science topics in early childhood can lead to a better understanding of scientific concepts in later life [39]. Exploring digital transformation in early childhood can lead to an understanding of digital technology processes [40]. Vogt and Hollenstein [9] can show that 
young children explore processes of digital transformation during pretend play and acquire important 21st-century skills through pretend play.

Children's interest and motivation for digital professions can be sparked in early years through digital education [9,40-43]. For example, children explore the concept of digital transformation amongst themselves and in play with the kindergarten teacher $[9,41,42]$. During pretend play, children demonstrate skills necessary for the digital future [10,41]. Pretend play promotes an active, creative, and critical use of digital technology for children to imagine themselves as professionals who actively shape digital transformation [9].

Play guided by teachers leads to high-quality play and provides children with learning opportunities in different areas [44,45]. Guided pretend play refers to the use of play to introduce curricular topics by providing materials and supporting pretend play [46]. Within guided pretend play, teachers have an important role to guide the focus on digital transformation, introducing ideas of transforming everyday processes and raising questions as to why something works or not $[9,47]$. Children rely on support in the problem-solving process from expert persons [4]. The presence of the kindergarten teacher is important in order to expand reasoning about digital processes, as the teacher asks questions or suggests paths for problem solving. As pretend play allows for anything to be assumed, stated, or done, the feedback of the kindergarten teacher can trigger further reasoning, such as asking about the reason for stating or doing something. The guidance of the kindergarten teacher is even more important, as direct feedback from the digital technology is missing. When children deal with real, functioning technology, feedback as to whether something works or not is instant. It could even be said that the direct feedback of the digital technology partially replaces feedback from the teacher [48]. As these pretend play impusles on digital transformation do not include any functionning devices, the feedback from the teacher is crucial in order to develop reasoning further.

Teachers need to be aware of digital processes in order to be able to provide highquality play guidance. Several initiatives seek to provide teacher training in digital competencies $[19,20]$. However, there is still a great need to develop this further. In early childhood teacher education, little time is devoted to how to teach STEM and digital technology [49-51]. Several studies found that early childhood educators perceive themselves to be badly equipped to teach STEM and digital technology [51] and are thus reluctant to include STEM and digital technology in kindergarten [49,52].

Based on the research literature, it can be assumed that problem solving could best be fostered in early childhood through pretend play [30] so that children get to know, understand, and apply functionalities and basic principles of the digital world. However, there is a lack of studies about problem-solving strategies during pretend play. Furthermore, the potential of guided pretend play for children's engagement with digital transformation processes and for the acquisition of 21st-century skills-in particular, digital problem solving — has as yet hardly been researched.

\subsection{Aims}

The present paper focuses on guided pretend play on topics of digital transformation to encourage young children to engage with processes of digital transformation and to acquire 21st-century skills. For this purpose, the present study developed pretend play inputs for kindergarten. The pretend play inputs included ideas for play corners and role-play situations, as well as ideas for enriching play with variations, in order for children to integrate topics related to digital transformation in free play. As a context to learn about digital problem solving, pretend play inputs on digital transformation can be set up [9]. Central to the pretend play inputs on digital transformation is the setting up of an information technology center (IT center) as a play corner in the kindergarten classroom. The children pretend to be an IT specialist, thus pretending to provide, install, and maintain hardware, software, and network components as well as localize and eliminate errors. Furthermore, an IT specialist instructs users in the use of equipment and takes care of repairs. The pretend play role of IT specialist allows for many digital problem-solving 
situations to be invented and played out. The IT center can be linked to other inputs of digital transformation. As examples, the IT specialists are summoned when the 3D-printer does not work, the police needs IT specialists to come up with a new solution for tracking, or a food laboratory seeks to automate production.

The focus of the present study is to explore children's ability to generate solutions to problems related to digital technology during guided pretend play in the context of an IT center play corner.

The following research questions are explored:

1. What kind of problems emerge during guided pretend play in the IT center?

2. In what way do children solve digital problems in guided pretend play?

3. What reasoning do children co-construct in guided pretend play as to the functioning of digital processes?

4. How do teachers foster problem-solving skills through guided pretend play?

\section{Materials and Methods}

The above research questions require a mixed-method design with regard to data analyses [53]. Qualitative analysis allows for distinguishing problem-solving approaches, whereas quantitative analysis is used to determine in what ways problem solving within pretend play differs with or without the teacher being present.

\subsection{Sample and Study Design}

In the context of the exploratory intervention study "We play the future", children's pretend play was analyzed in order to investigate the problem-solving strategies that the children use when solving digital problems. In addition, the analysis sought to explore how children explain problem-solving processes and how the teachers support such processes. The intervention study was conducted in 15 kindergartens in Switzerland. The teachers were recruited through advertisements in professional magazines and online.

The intervention consisted of professional development and the implementation of inputs for pretended play on digital transformation. The kindergarten teachers attended a half-day professional development course provided by the research team. They then implemented at least three pretend play inputs in their kindergarten classrooms for 3.5 months. The kindergarten teachers introduced the pretend play inputs on digital transformation by taking part in the role play and modeling digital problem-solving processes. Subsequently, the children could play on their own during free play (ca. one to two hours per day) and the teacher were encouraged to participate in the play from time to time in order to foster ideas and support reasoning co-constructively.

The participated children were 4 to 6 years old. No data about the children's characteristics such as socio-economic background or prior knowledge were collected. Kindergarten is part of compulsory education in Switzerland. Children attend kindergarten five days a week for a total of approximately $18 \mathrm{~h}$ per week. Sequences of free play are included every day for 1 to $1.5 \mathrm{~h}$. Kindergarten education follows a competence-based curriculum. Information technology and media is regarded as a cross-sectional area [54].

\subsection{Pretend Play Inputs}

As part of the project "We play the future", pretend play inputs were developed in eight different areas of digital transformation [55]. The project uses existing play corners and imaginatively expands them through the theme of digital transformation (the family corner becomes a smart home corner) and sets up new play corners, for example, an IT center. The eight inputs are based on current digital transformation initiatives [7] and possible future developments and include the core digital processes needed for digital transformation, such as data transfer via sensors and microchips. In addition, care was taken to ensure that the topics were closely related to the everyday experience of young children. The inputs for the pretend play include eight areas: (1) IT center, (2) robotics, 
(3) 3D printer, (4) autonomous vehicles, (5) Internet of Things, (6) police and tracking, (7) online shopping, and (8) food laboratory [9].

As part of the project, the participating kindergartens were provided with various materials for the pretend play (e.g., old laptops, wooden tablets with replaceable cardboard surfaces) as well as concrete descriptions of how to introduce and implement the inputs in the kindergarten [55]. These materials only included non-functioning devices in order to support pretending and to concentrate on co-constructive reasoning on digital transformation.

\subsection{Data Collection and Analysis}

In view of the exploratory research questions, a qualitative design was devised for this research project, relying on video observation. The children's play was video recorded on two occasions within 3.5 months. The children's play was filmed using two video cameras on tripods and additional small microphones placed in the play area. Overall, $45 \mathrm{~h}$ of recorded video material was collected. The teachers repeatedly joined the pretend play. Written informed consent was obtained from the parents and the teachers for the videos. On the day of the video recordings, the children could decide independently whether they wanted to participate in the video recordings or devote themselves to another play area.

The data were analyzed using mainly qualitative content analysis [56] within a "qualitative-dominated crossover study" [53,57]. For the analysis of the problem-solving processes and the problem-solving strategies, 21 videos (almost $13 \mathrm{~h}$ ) were selected, which all involved a sequence with the IT center. These $13 \mathrm{~h}$ of video material were analyzed in depth. The video material was coded using MAXQDA 2020. A category system was developed in advance based on theoretical concepts of problem solving [56]. During coding, some categories based on open coding were added (see Table 1).

From the 12:50:00 h of video material, a total of $N=75$ sequences were identified as problem-solving situations. Situations were coded as problem-solving situations if a problem was clearly expressed (e.g., "The tablet is broken," "The refrigerator no longer works," "We want to create a new app"). Each problem-solving situation was subsequently coded in more detail. Each situation was coded along the following lines: (1) teacherguided problem-solving process, (2) type of problem, (3) phase of problem solving, and (4) problem-solving strategy (see Table 1).

Nearly $20 \%$ of the video material was randomly selected and coded by two persons, independently of each other. The double-coder inter-reliability was substantial, with a kappa of $\kappa=0.71[58]$.

In order to compare the problem-solving processes with or without the teacher being present, quantitative analyses were used. With the help of chi-square test, the frequencies of problem-solving phases and strategies as well as the length of these sequences were tested on the significance between pretend play with or without the teachers' presence. This follows the mixed methods design of a qualitative-dominated crossover study, whereby quantitative analysis follows dominantly qualitative data collection and analysis [57]. 
Table 1. Extract from category system.

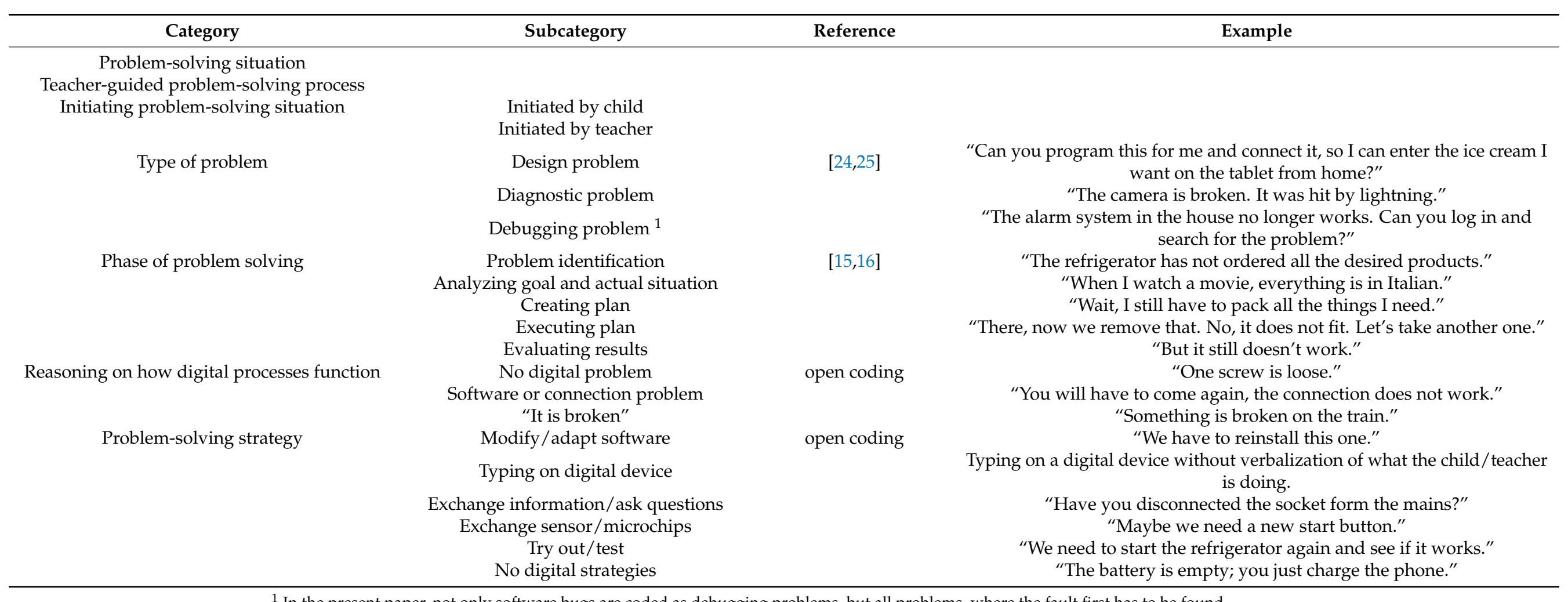

${ }^{1}$ In the present paper, not only software bugs are coded as debugging problems, but all problems, where the fault first has to be found. 


\section{Results}

First, an overview of the frequency of the problem-solving sequences will be given, then the results will be presented following the research questions.

From the 12:50:00 h of video material involving the IT center, 75 sequences of problem solving were identified, totaling 02:32:51 h. In all 15 kindergartens, problem-solving sequences involving the IT center were identified. It is clear that establishing a play corner as an IT center facilitates pretend play with digital problem solving. In 10 of the 15 kindergartens, 32 sequences were guided by the kindergarten teacher (01:46:05 h). Thus, problem-solving sequences had a mean duration of 01:19 min when children played on their own, whereas the mean duration when guided by the kindergarten teacher was 03:00 min. The difference was statistically significant (exact Mann-Whitney U-test: $U=686$, $p<0.05$ ). The effect size was $r=0.25$, which is a small effect [59].

Children initiated $57(76 \%)$ of these problem situations; the kindergarten teachers initiated 18 situations. From the sequences with the teachers present, $44 \%$ were initiated by the children and $56 \%$ by the teachers.

The presentation of the results follows the research questions: (1) problems arising, (2) problem-solving strategies, and (3) reasoning about digital technology. For each of these research questions, the results were analyzed by comparing pretend play sequences with or without the teacher the teacher being present, thus providing results for research question 4 (support of the teacher for problem solving). The qualitative analysis of the problem-solving sequences is illustrated using excerpts. Then frequencies of different phases and digital strategies are summarized. In order to compare pretend play sequences with and without the teachers' presence, chi-square tests were used to determine whether the differences in frequencies were significant. In the Results section, quantitative analysis using chi-square tests and data on frequencies follows the qualitative analysis, which is based on excerpts and content analysis [53,56].

\subsection{Problems That Arise during Guided Pretend Play, Where the IT Center Is Involved}

During the 75 sequences of problem solving, 81 codes regarding the type of problem were assigned. A total of 40 codes for type of problem were given in situations with the kindergarten teacher present. A total of 72 of all of the types of problems coded were debugging problems ( $n=72$; with the kindergarten teacher present: $n=33$ ). Five design problems and four diagnostic problems occurred during pretend play in the IT center, most of them when the kindergarten teacher was present.

The following two situations represent typical debugging problem-solving situations when children played amongst themselves:

Excerpt 1:

A customer (child 1) calls the IT center and describes the following: "My cell phone is broken" (17:46). The IT specialist (child 2) responds and asks the customer to come over. "Hello, what's broken?" (17:56). The customer explains that the phone is no longer working: "It doesn't work anymore" (18:04). The IT specialist takes care of the problem and pretends to screw the phone with the screwdriver (18:14). "So, finished!" (18:18). The customer picks up his phone and leaves the IT center.

\section{Excerpt 2:}

A child, pretending to be a pirate, calls the IT center and explains that the motor of the autonomous sailing pirate ship is not functioning properly (06:08). The IT specialist types on her laptop (06:18). Now she asks the pirate if the motor is working again (06:27). "No" (06:30). The IT specialist types again on her laptop and asks once again "Does it work now?" (06:36). Now, the motor is working again (06:42).

In excerpt 1 the source of the problem was unknown; the customer said only, "The phone is no longer working." In the play situation, the IT specialist came up with reasoning for why the phone did not work anymore. The IT specialist identified a non-digital problem. It was just a problem with a screw, and he solved the problem with a screwdriver. 
In comparison, in excerpt 2 , the IT specialist identified a software problem, as she was typing on her laptop and used the remote access. The problem-solving process needed a short test phase and a small correction, as the IT specialist had to type on the laptop again before the problem was solved. Nevertheless, the problem-solving strategy was just typing on a digital device without any verbalization of what the IT specialist was doing.

Excerpt 3 shows a situation again without the guidance of the kindergarten teacher. The children identified a problem regarding the connection between the tablet and the refrigerator.

Excerpt 3:

The IT specialists (children 1 and 2) are performing a technical check in the home corner: "We're checking to make sure all the equipment is okay" (19:14). The IT specialist (child 2) notices that the refrigerator door cannot be opened and that this is probably due to the defective microchip: "But that doesn't work... THAT doesn't work" (19:24). The other IT specialist (child 1) reaches for the tablet and tries to scan the microchip on the refrigerator door with it. The resident (child 3) intervenes because the IT specialist has not activated the scanning app on the tablet (19:34). The IT specialists (children 1 and 2) then scan the microchip and find that it still does not work: "But it still doesn't work" (19:45). The IT specialist (child 2) checks the SIM card and finds that the problem is caused by a defect on the SIM card: "Now we have to look at the SIM card. The SIM card is not working anymore." (19:50). The IT specialists want to replace the SIM card (19:54). The IT specialist (1) goes and organizes a screwdriver. Following this, the IT specialist (2) screws and says, "So, now I got it" (20:45). The IT specialist (1) scans the microchip again with the tablet and checks it for functionality: "Now it works again" (21:58).

The sequence highlights a number of problem-solving strategies: with (1) the exchange of the microchip (hardware), (2) the exchange of information (the resident advises that the scanning app has not been activated), and (3) the testing of functions (scan procedure). The analysis of the situation shows that the children were able to pretend to solve a more complex problem situation and to use different problem-solving strategies. They created a plan to (1) have a look at the SIM card, (2) organize a screwdriver, and (3) pretend to screw out the SIM card-and they verbalized what they were doing. This kind of more complex problem-solving situation was rare when the children played amongst themselves without the guidance of the kindergarten teacher. More often, when children played amongst themselves, problem solving involved neither digital strategies nor verbalization of the digital strategy, as in excerpts 1 and 2 above. The children pretended to solve the problems in a very brief manner in excerpts 1 and 2 and tended to use conventional strategies (screwdriver, excerpt 1) to solve the problem or did not verbalize what they did (typing on the laptop, excerpt 2). By contrast, in excerpt 3 the children used different problem-solving strategies and partly verbalized what they did.

The following situation represents a problem-solving situation during guided pretend play, where the kindergarten teacher participated:

Excerpt 4:

In the IT center, three IT specialists are pretending to be working, with child 1 on a tablet, child 2 at the computer, and the teacher sitting in between the children also in the role of one of the IT specialists. A customer (child 3) comes to the IT center with a laptop and says to one of the IT specialists (child 1), "The computer is broken" (04:04). The teacher, in the role of a fellow IT specialist, guides child 1 to ask the customer, "What is broken?" (04:28). The customer explains, "I don't know either, it somehow ... When you watch a movie, the movie plays in Italian" (04:32). The IT specialist (child 1) asks what language the customer needs for the videos (04:53). The customer clarifies the language "English and some more French" (05:02). The teacher involves the other IT specialist (child 2) and asks the child, "Can you please log in?" (04:58) At the same time, the IT specialist (child 1) is busy with the tablet and asks the customer, "Is this disk broken?" (05:10). The customer is shown two different disks on the tablet: "There is this one or that one" 
(05:14). The teacher explains to the customer that the IT specialist (child 2) will now log into the system (05:26). The IT specialist (2) logs in on the computer and starts typing. The IT specialist (1) points at his tablet and says to the other IT specialists, "Yes, that is right. It's not the language they speak" (0:05:40). The teacher pretends to notice an error message on the computer: "Ah yes, look there's an error message. We see it there" (05:52). She asks the IT specialist (child 2), "Can you reprogram that?" (05:57). The teacher checks with the customer that English is the desired language (06:01). The customer says, "In English and in French" (06:05). Now the teacher joins child 2 at the computer and also types and verbalizes that she is reprogramming the language: "Ok, look, the error message is gone. I think, we've solved the problem. However, wait a moment, I just want to have a look again, because yesterday I had ..." (06:24). The teacher is typing on the keyboard of the computer again and says, "Oh, no, now the language is Chinese. Please, try to reprogram, IT specialist (child 2), you can do that" (06:34). The teacher asks the customer if it is right, that everything on his laptop is in Chinese. The customer looks at his laptop and says, "Yes." The task of reprogramming is again given to the IT specialist (child 2) (06:39). After a new attempt (typing on the keyboard) the IT specialist (child 2) solves the problem, and the customer confirms that the correct language is now set: "It's all good" (06:55).

This excerpt illustrates the finding that with the teachers' guidance, the problemsolving processes were significantly longer. A whole process of problem solving occurred. Firstly, child 1 identified the problem (05:10). Thereafter, the three IT specialists, the two children and the teacher, suggested a problem-solving plan (05:26). The teacher and child 2 were executing the plan and the teacher was evaluating it (06:34). After a new reprogramming phase, the IT specialists solved the problem, and the customer confirmed that everything was now good. During the problem-solving process, the teacher supported the IT specialists to ask questions to obtain more information about the problem (04:28) and verbalized what she was thinking (06:24). The teacher pretended to make a mistake. She reprogrammed the language setting to a language that was not requested. Thus, the problem was not yet solved and it needed further problem solving. The kindergarten teacher, in her role as an IT specialist, encouraged child 2 as IT specialist to take charge of reprograming and solving the problem. The children and the teacher, in their roles as IT specialists, used different problem-solving strategies, such as trying out and testing, exchanging information, posing questions, typing on a digital device, and modifying the software and the settings.

\subsection{How Children Solve Digital Problems}

Problem identification is the first step in the problem-solving process. Once the problem has been identified, the problem-solving process includes phases such as analyzing the goal and the actual situation, creating a plan, executing a plan, and evaluating the results $[15,16]$. The results indicate no significant differences between the frequencies of problem-solving phases that occurred during guided pretend play with and without the teachers present $\left(\chi^{2}=5.46, d f=4 ; p=0.24\right)$. Looking at the frequencies of phases beyond problem identification, on average two additional phases occurred with the teacher present, whereas without the teacher, only one additional phase occurred on average. It is noticeable that many problems were identified during the analyzed pretend play situations $(n=114)$. For example, one child contacted the IT center and told them that something had happened. The IT specialist asked what kind of problem it was and the child answered that something was broken. After that, nothing else was done or mentioned on that problem situation and the children's play continued with another focus. No further phase of the problem-solving process began. For the processes where a second phase of problem solving followed the identification, the next steps were also often very brief, particularly when children played on their own. They identified a problem, then typed on a digital device, and after that gave the device back without verbalizing what they did. Figure 2 shows the frequency of all 
processes across all problem-solving sequences. In Table $2 \mathrm{a}$ variety of different successions of problem-solving phases found in the pretend play situations is visualized.

Table 2. Possible problem situations and the corresponding problem-solving process.

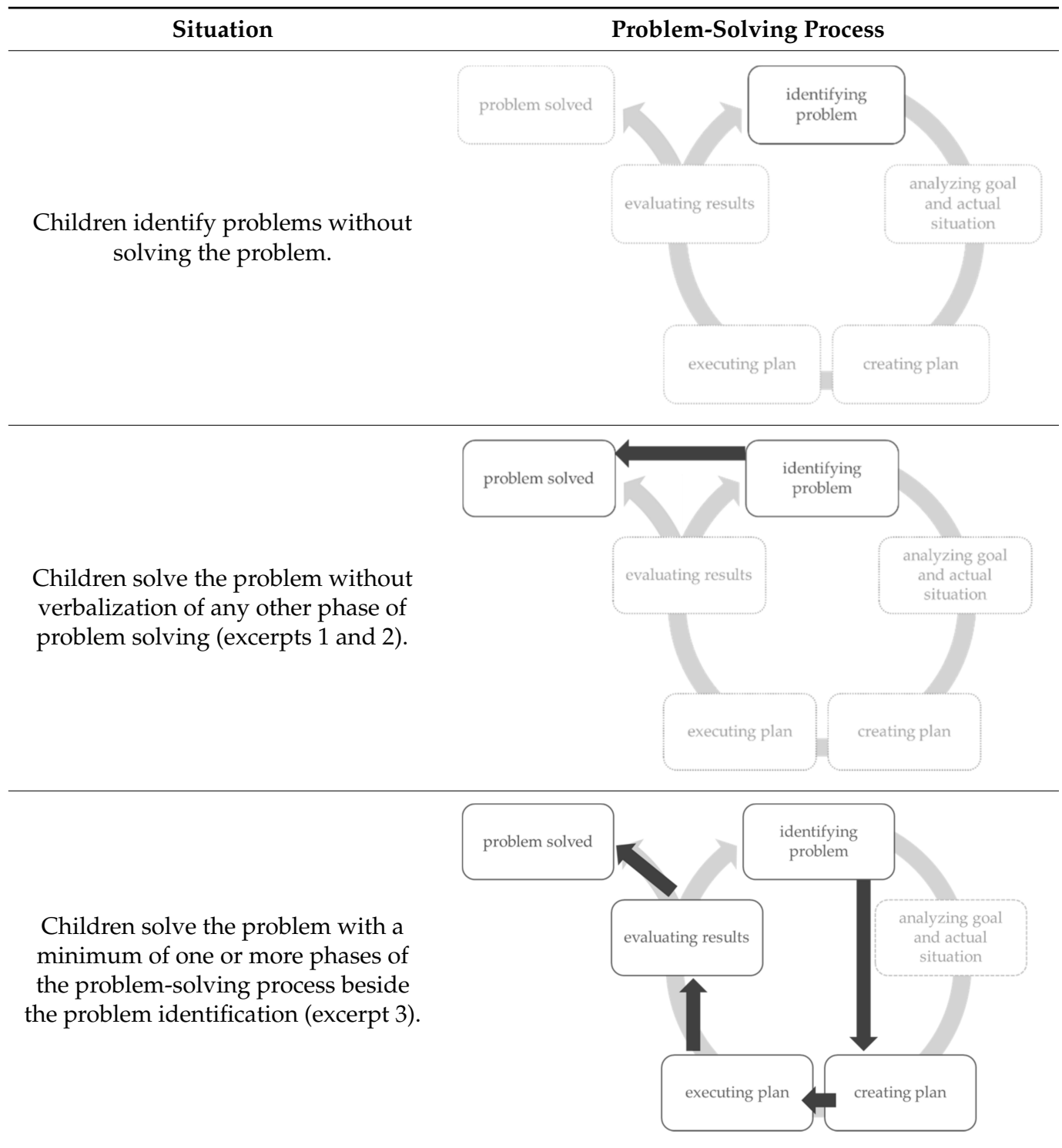

Children solve the problem without verbalization of any other phase of problem solving (excerpts 1 and 2).

Children solve the problem with a minimum of one or more phases of the problem-solving process beside the problem identification (excerpt 3 ).

Children solve the problem, with the support of the kindergarten teacher, with a minimum of one or more phases of the problem-solving process once the problem identification is complete (excerpt 4).

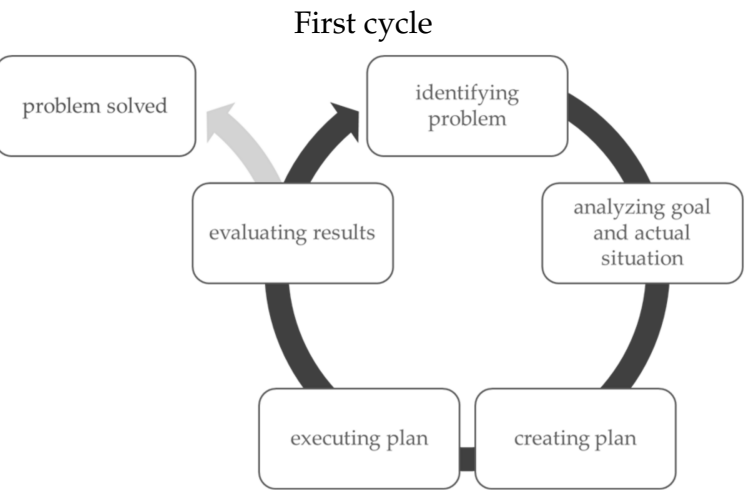


Table 2. Cont.
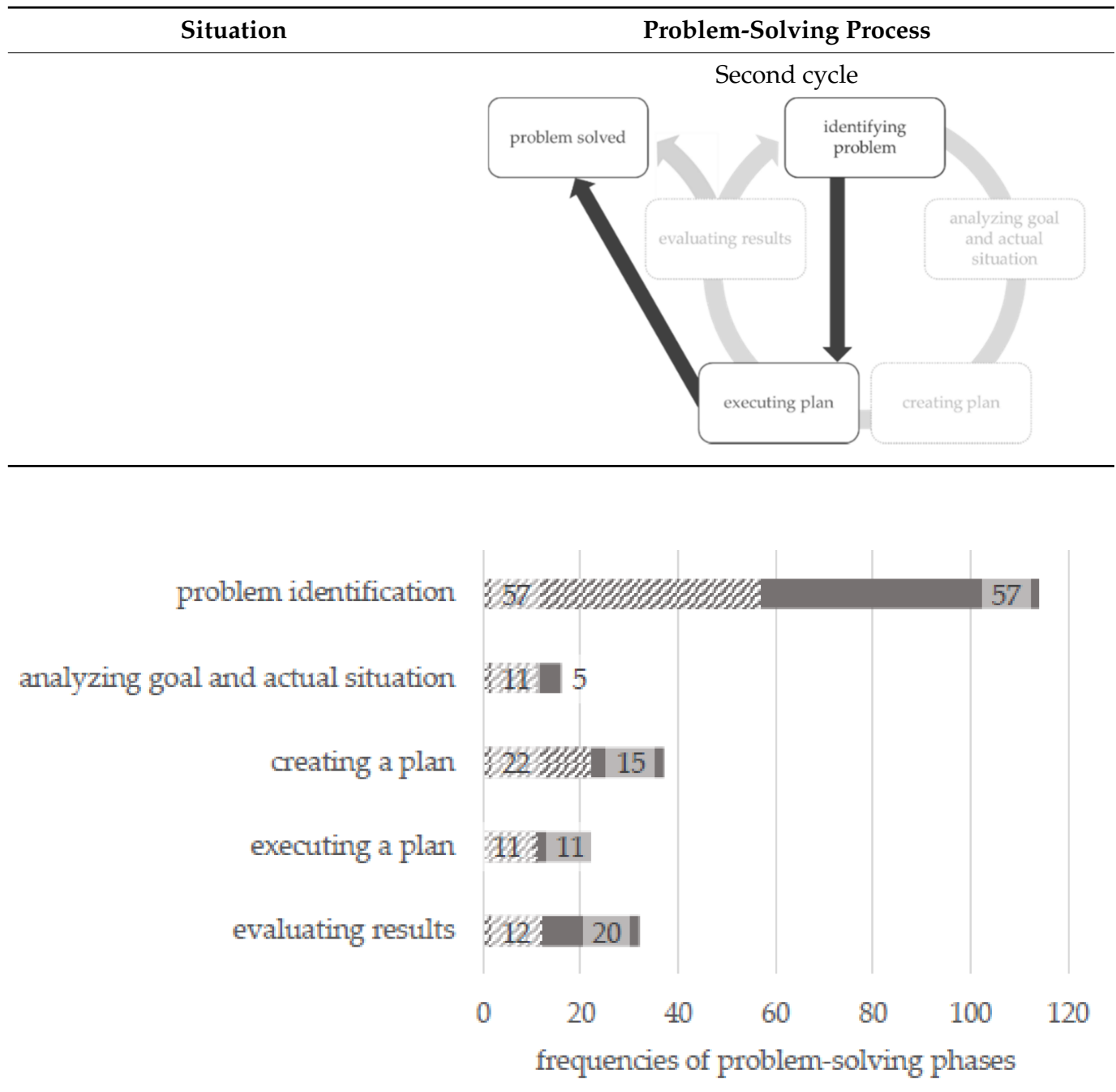

\# guided pretend play with teacher $\quad$ guided pretend play without teacher

Figure 2. Problem-solving phases arising during guided pretend play.

Children used different strategies during the problem-solving sequences. In total, 122 problem-solving strategies were coded during the 75 problem-solving situations. A total of 94 of these 122 problem-solving strategies were coded during guided pretend play with the teacher. Most of the problem-solving strategies were digital strategies $(n=104)$. A strategy was coded as "no digital strategy" when the problem-solving strategy involved actions such as turning off the device, recharging, or using a screwdriver.

When guided by the teacher, the children used significantly more problem-solving strategies compared to playing amongst themselves $\left(\chi^{2}=19.42, d f=5 ; p=0.002\right)$. 
Furthermore, the results demonstrate that the children could solve the identified problems using digital strategies. Figure 3 shows the frequency of problem-solving strategies in total and during guided pretend play. Children used strategies not relying on digital problem solving (e.g., solving the problem with a screwdriver) $n=18$ times in total and $n=13(72 \%)$ times during guided pretend play with the kindergarten teacher. Children mostly modified or adapted software $(n=45)$ : They programmed, installed an app or a function, or modified a setting. A total of 38 of these 45 "modify / adapt software" codes were coded during guided pretend play with the teacher (84\%). Just typing on a digital device (e.g., a computer, laptop, or tablet) without any verbalization of what they were doing was the second most frequent, at $n=25$ of the $N=122$ problem-solving strategies. A total of $14(56 \%)$ of these situations arose during guided pretend play with the kindergarten teacher. Children exchanged information or asked questions 17 times, for example, to get more information about the problem. In $68 \%(n=11)$ of these $n=17$ situations, children did so while guided by the kindergarten teacher. In $n=12$ times, children exchanged a sensor or microchip, $75 \%(n=9)$ during guided pretend play with the teacher. Furthermore, the children tried out or tested the function $n=10$ times, $n=9$ of them guided by the kindergarten teacher.

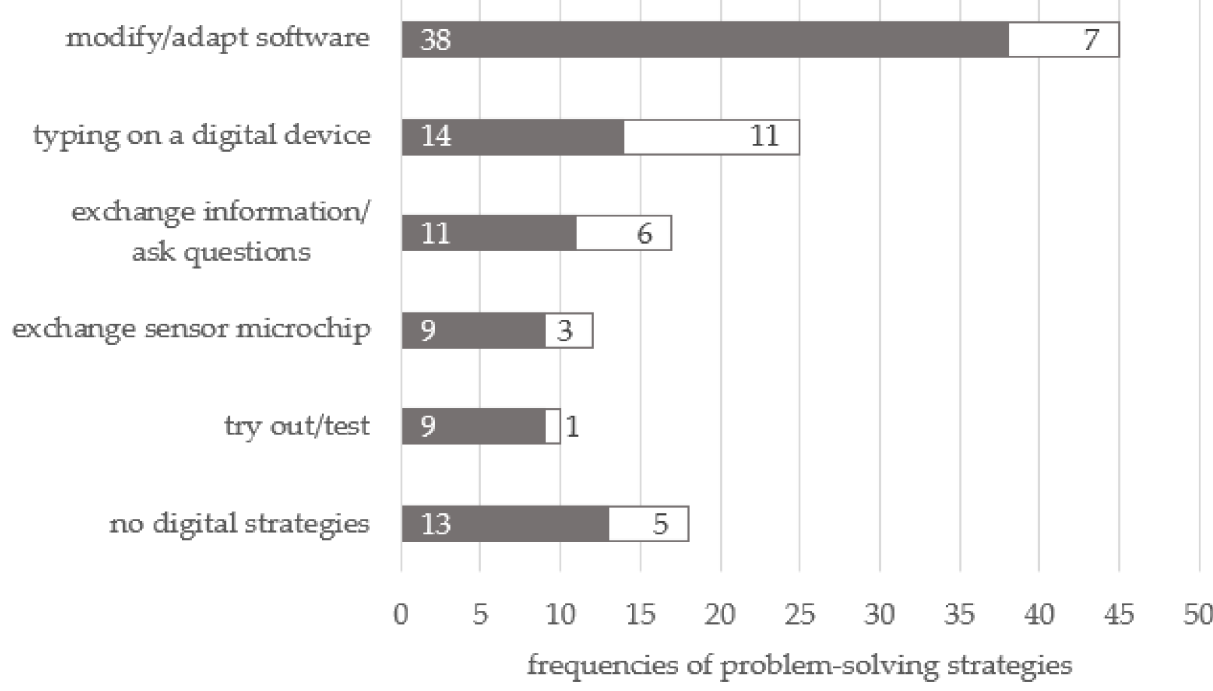

घuided pretend play with teacher $\quad \square$ guided pretend play without teacher

Figure 3. Frequency of children's strategies to solve problems.

\subsection{Children's Reasoning about How Digital Processes Function}

The reasoning about how digital processes function is depicted in Figure 4. The results indicate that children significantly more often provided reasoning on how digital processes function with the kindergarten teacher present than without the teacher present $\left(\chi^{2}=22.72\right.$, $d f=2 ; p<0.001$ ). A total of 52 occurrences involved just "it is broken" without any special explanation. Only in $n=15$ of these situations did children identify such an unspecific problem during guided pretend play with the teacher. By comparison, children identified a software or connection problem (e.g., a wrong setting, error message, or connection issue) in $n=50$ situations in total, and within these situations, $n=37$ were guided by the kindergarten teacher. Children identified no digital problem (e.g., a screw is loose or lightning hit the rocket) $n=12$ times, and in half of those $(n=6)$ the teacher was present. 




Figure 4. Frequency of children's reasoning about how digital processes function.

\section{Discussion}

The present paper aims to explore children's ability to generate solutions to digitalrelated problems during guided pretend play. The analysis of all sequences of the IT center shows that compared to the total duration of the IT center sequences (12:50:00 h), only little time was used for problem sequences (02:32:51 h, including 01:46:05 h with teachers present).

To sum up, the guided pretend play in the IT center shows potential for problemsolving sequences, which often the children initiated and the teacher expanded. The problem-solving sequences with the teacher were on average twice as long as the duration when the children played alone.

The findings indicate that the pretend play inputs on digital transformation enabled children to explore cognitive problem-solving processes and to acquire an understanding of digital processes, thus possibly supporting the acquisition of computational thinking skills [21]. Most of the problem-solving situations arose with the children initiating a problem. During guided pretend play, the children identified many digital technologyrelated problems and solved them with digital strategies such as devising new applications and installing software. The children identified problems in the play situation, tried to debug (i.e., found the error in the language setting), programmed (i.e., secured a door with a digital code), and installed (i.e., connected a new sensor to the coffee machine). These observations show that the children got to know, understood, and applied functionalities and basic principles of digital technology in their pretend play [5] and acquired crucial competences needed for the digital future $[10,60]$. Nevertheless, the children's reasoning about how digital processes function was often unspecific ("It is broken") when they play amongst themselves and more specific when the kindergarten teacher played with them.

Guided pretend play, in which the kindergarten teachers directly participated in the play, revealed much potential for extensive problem solving, involving reasoning on digital functioning. The results show that during pretend play, digital problem-solving processes with teacher involvement were significantly longer and more extensive in terms of employing problem-solving strategies and engaging in reasoning as to how digital technology functions. Specific problem-solving strategies arose largely during guided pretend play situations with the teacher present, such as modifying or adapting software as well as trying or testing problem solutions. The reasoning about how digital processes function was verbalized more often and a digital device was not just deemed broken. The problemsolving process did not overall differ in relation to the kind of problem-solving phases between the situations with or without the support of the kindergarten teacher. However, 
it can be concluded that the teacher's guidance and participation in the play encouraged the children to see the solution of the problem in the software, to exchange ideas and ask questions, and to try out problem solutions. The potential of guided play is emphasized by Hirsh-Pasek et al. [30], who promote guided pretend play with the kindergarten teacher to foster problem-solving skills. The teacher's participation is even more important because the children do not receive direct feedback from functioning technology, which in other contexts has been found to partly replace the teacher's support [48].

Pretend play guidance can be a promising way to promote the exploration of digital transformation topics for young children in relation to digital transformation. This is in line with other studies that show that the quality of free play is improved through guided pretend play [44,45]. Guiding pretend play on digital transformation requires teachers to establish play areas with materials that simulate digital artefacts but also to actively play along, modeling understanding of digital processes and encouraging children's ideas. Nevertheless, the results underline the importance of further training on digital expertise in order to be able to recognize relevant play situations and draw digital technology correctly into the play situation. Often teachers in early childhood education do not feel sufficiently prepared for digital education [49-51]. In the present sample, teachers completed half a day's professional development about digital transformation processes, guided pretend play, and fostering gender equality in technology education. The current results underline the importance of providing teachers with further training, specifically on problem-solving processes during guided pretend play. Problem-solving processes in the digital context are very complex. Teachers therefore need more in-depth training to support children's problem solving during guided pretend play.

There are limitations to the research findings that need to be considered: Firstly, learning processes were not observed over a longer period. Consequently, it is not possible to draw any assumptions about children's development of crucial 21st-century skills. Additionally, we do not yet know what kind of digital competence kindergarten teachers need in order to facilitate high-quality pretend play in the area of digital transformation. Further research could capture the development of children's skills and motivation during a longer period while playing with these kind of pretend play inputs, as well as focusing on kindergarten teachers' competence in fostering digital learning through pretend play. Secondly, the explorative intervention study includes neither a comparison with other approaches of digital education (e.g., picture book, coding a robot, programming on a computer) nor other approaches to learn problem-solving skills (e.g., productive failure vs. direct instruction [28]). Pretend play fosters problem solving by encouraging reasoning as to what the problem with a digital device could be or about the digital transformation process as a whole. Nevertheless, the results should be replicated and expanded with further studies, especially quantitative studies-for example, with a larger number of problem-solving situations.

The results reveal that playing with the kindergarten teacher was characterized by a higher quality of pretend play [44,45], a more complex and extensive problem-solving process, and a deeper and more extensive reasoning on digital transformation.

\section{Conclusions}

The findings indicate that children initiate problem-solving situations and identify problems. This is in line with the OECD [16], which identified that "problem solving begins with recognizing that a problem situation exists and establishing an understanding of the nature of the situation." However, problem identification does not automatically result in a problem-solving process in guided pretend play; rather, it requires a sustained dialogue with other children or the teacher. Consequently, the results indicate that solving digital problems with digital strategies is more common when the teacher is involved in the process, as teachers verbalize their reasoning, ask questions, and model digital problemsolving strategies. In the pretend play inputs on digital transformation, the children can practice cognitive problem-solving processes and acquire an understanding of digital 
processes. Additionally, the children foster the different processes during problem solving. Kindergarten teachers can help structure the problem-solving process. Structuring is central to acquiring problem-solving skills [12] and stimulating reasoning about how digital technology functions. All these processes seem to be important learning opportunities for the children to develop computational thinking [21]. The results emphasize the assumed potential of guided pretend play for children's engagement with digital processes and digital problem-solving processes.

Author Contributions: Conceptualization, L.H. and F.V.; methodology, L.H., S.T. and F.V.; validation, L.H. and S.T.; formal analysis, L.H. and S.T.; investigation, L.H. and F.V.; data curation, L.H. and F.V.; writing—original draft preparation, L.H. and S.T.; writing—review and editing, F.V.; visualization, L.H.; supervision, F.V.; project administration, L.H.; funding acquisition, F.V. All authors have read and agreed to the published version of the manuscript.

Funding: This research was funded by a grant from the Swiss Academies of Arts and Science as part of the National Programme on STEM Education with a focus on digital transformation (T1/wP 2-3).

Institutional Review Board Statement: All subjects gave their informed consent for inclusion before they participated in the study. Written informed consent was obtained from the parents and the teachers for the videos. The consent was approved by the legal office of the St. Gallen University of Teacher Education. On the day of the video recordings, the children could decide independently whether they wanted to participate in the video recordings or devote themselves to another play area. There is no ethic committee established at the St. Gallen University of Teacher Education, therefore no approval could be obtained. The St. Gallen University of Teacher Education upholds the regulation of the Swiss Academies, these were followed throughout.

Informed Consent Statement: Informed consent was obtained from all subjects involved in the study.

Data Availability Statement: The data that support the findings of this study are available from the corresponding author upon reasonable request.

Acknowledgments: We would like to thank all kindergarten teachers and children for playing the future with us.

Conflicts of Interest: The authors declare no conflict of interest. The funders had no role in the design of the study; in the collection, analyses, or interpretation of data; in the writing of the manuscript, or in the decision to publish the results.

\section{References}

1. Shedd, A.N.; Scott, A.K.; McCullough, J.M. Careers in Engineering, Mathematics, Science, and Related Fields: A Selected Bibliography. Bulletin 1961, 8, 1-43.

2. Fusaro, M.; Smith, M.C. Preschoolers' inquisitiveness and science-relevant problem solving. ECRQ 2018, 42, 119-127. [CrossRef]

3. McClure, E.R.; Guernsey, L.; Clements, D.H.; Bales, S.N.; Nichols, J.; Kendall-Taylor, N.; Levine, M.H. STEM Starts Early: Grounding Science, Technology, Engineering, and Math Education in Early Childhood; Joan Ganz Cooney Center at Sesame Workshop: New York, NY, USA, 2017.

4. Ismail, N.; Ismail, K.; Aun, N.S.M. The Effect of Maternal Scaffolding on Problem Solving Skills during Early Childhood. J. Appl. Behav. Sci. 2019, 14, 76-89.

5. Reuter, T.; Weber, A.; Nitz, S.; Leuchter, M. Problemlösen in digitalen Kontexten. Empirische Pädagogik 2021, 35, 5-18.

6. Schallmo, D.R.A. Jetzt Digital Transformieren; Springer: Wiesbaden, Germany, 2016.

7. World Economic Form Accenture. Digital Transformation Initiative. Unlocking $\$ 100$ Trillion for Business and Society from Digital Transformation. 2017. Available online: http://reports.weforum.org/digital-transformation/wp-content/blogs.dir/94/mp/ files/pages/files/dti-executive-summary-20180510.pdf (accessed on 4 January 2022).

8. Turja, L.; Endepohls-Ulpe, M.; Chatoney, M. A conceptual framework for developing the curriculum and delivery of technology education in early childhood. Int. J. Technol. Des. Educ. 2009, 19, 353-365. [CrossRef]

9. Vogt, F.; Hollenstein, L. Exploring digital transformation through pretend play in kindergarten. Br. J. Educ. Technol. 2021, 52, 2130-2144. [CrossRef]

10. Van Laar, E.; Van Deursen, A.J.; Van Dijk, J.A.; De Haan, J. The relation between 21st-century skills and digital skills: A systematic literature review. Comput. Hum. Behav. 2017, 72, 577-588. [CrossRef]

11. Antón-Sancho, Á.; Vergara, D.; Fernández-Arias, P. Self-Assessment of Soft Skills of University Teachers from Countries with a Low Level of Digital Competence. Electronics 2021, 10, 2532. [CrossRef] 
12. Priemer, B.; Eilerts, K.; Filler, A.; Pinkwart, N.; Rösken-Winter, B.; Tiemann, R.; Zu Belzen, A.U. A framework to foster problemsolving in STEM and computing education. Res. Sci. Technol. Educ. 2020, 38, 105-130. [CrossRef]

13. Aschauer, W.; Haim, K.; Weber, C. A Contribution to Scientific Creativity: A Validation Study Measuring Divergent Problem Solving Ability. Creat Res. J. 2021, 1-18. [CrossRef]

14. DeHaan, R.L. Teaching creativity and inventive problem solving in science. CBE Life Sci. Educ. 2009, 8, 172-181. [CrossRef] [PubMed]

15. Betsch, T.; Funke, J.; Plessner, H. Denken-Urteilen, Entscheiden, Problemlösen; Springer: Wiesbaden, Germany, 2011.

16. OECD. PISA 2012 Assessment and Analytical Framework: Mathematics, Reading, Science, Problem Solving and Financial Literacy; OECD Publishing: Paris, France, 2013.

17. Funke, J. Komplexes Problemlösen-Möglichkeiten deduktivistischen Vorgehens. In Allgemeine Psychologie und Deduktivistische Methodologie; Erdfelder, E., Funke, J., Eds.; Vandenhoeck Ruprecht: Göttingen, Germany, 2004; pp. 281-300.

18. DeLoache, J.S.; Miller, K.F.; Pierroutsakos, S.L. Reasoning and problem solving. In Handbook of Child Psychology: Volume 2: Cognition, Perception, and Language; John Wiley Sons Inc.: Hoboken, NJ, USA, 1998; pp. 801-850.

19. NGSS Lead States. Next Generation Science Standards: For States, by State; National Academies Press: Washington, DC, USA, 2013.

20. Kultusministerkonferenz (KMK). Bildung in der Digitalen Welt: Strategie der Kultusministerkonferenz; KMK: Berlin, Germany, 2016.

21. Bers, M.U.; Flannery, L.; Kazakoff, E.R.; Sullivan, A. Computational thinking and tinkering: Exploration of an early childhood robotics curriculum. Comput. Educ. 2014, 72, 145-157. [CrossRef]

22. Grover, S.; Pea, R. Computational thinking in K-12: A review of the state of the field. Educ. Res. 2013, 42, 38-43. [CrossRef]

23. Atmatzidou, S.; Demetriadis, S. Advancing students' computational thinking skills through educational robotics: A study on age and gender relevant differences. Rob. Auton. Syst. 2016, 75, 661-670. [CrossRef]

24. Müller, C. Problem-based Learning erfolgreich gestalten. In Hochschullehre Variantenreich Gestalten. Ansätze, Methoden und Beispiele Rund um Kompetenzorientierung; Bachmann, H., Ed.; Hep: Bern, Switzerland, 2013; pp. 50-77.

25. Jonassen, D.H. Toward a design theory of problem solving. Educ. Technol. Res. Dev. 2000, 48, 63-85. [CrossRef]

26. McCauley, R.; Fitzgerald, S.; Lewandowski, G.; Murphy, L.; Simon, B.; Thomas, L.; Zander, C. Debugging: A review of the literature from an educational perspective. Int. Conf. Comput. Sci. Educ. 2008, 18, 67-92. [CrossRef]

27. Kapur, M.; Bielaczyc, K. Designing for productive failure. J. Learn. Sci. 2012, 21, 45-83. [CrossRef]

28. Kapur, M. Productive failure. Cogn. Instr. 2008, 26, 379-424. [CrossRef]

29. Kjällander, S.; Mannila, L.; Åkerfeldt, A.; Heintz, F. Elementary Students' First Approach to Computational Thinking and Programming. Sci. Educ. 2021, 11, 80. [CrossRef]

30. Hirsh-Pasek, K.; Golinkoff, R.M.; Berk, L.E.; Singer, D. A Mandate for Playful Learning in Preschool: Applying the Scientific Evidence; University Press: Oxford, UK, 2009.

31. Aras, S. Free play in early childhood education: A phenomenological study. Early Child Dev. Care 2016, 186, 1173-1184. [CrossRef]

32. Weber, A.M.; Reuter, T.; Leuchter, M. The impact of a construction play on 5-to 6-year-old children's reasoning about stability. Front. Psychol. 2020, 11, 1737. [CrossRef] [PubMed]

33. Sundqvist, P.; Nilsson, T. Technology education in preschool: Providing opportunities for children to use artifacts and to create. Int. J. Technol. Des. Educ. 2018, 28, 29-51. [CrossRef]

34. Fleer, M. Scientific Playworlds: A model of teaching science in play-based settings. Res. Sci. Educ. 2019, 49, 1257-1278. [CrossRef]

35. Forman, G.E. When 2-Year-Olds and 3-Year-Olds Think Like Scientists. ECRP 2010, 12, 1-6.

36. Zaldívar-Colado, A.; Alvarado-Vázquez, R.I.; Rubio-Patrón, D.E. Evaluation of Using Mathematics Educational Software for the Learning of First-Year Primary School Students. Educ. Sci. 2017, 7, 79. [CrossRef]

37. Fridman, R.; Eden, S.; Spektor-Levy, O. Nascent Inquiry, Metacognitive, and Self-Regulation Capabilities Among Preschoolers During Scientific Exploration. Front. Psychol. 2020, 11, 1790. [CrossRef]

38. Deichmann, F.; Ahnert, L. The terrible twos: How children cope with frustration and tantrums and the effect of maternal and paternal behaviors. Infancy 2021, 26, 469-493. [CrossRef]

39. Eshach, H.; Fried, M.N. Should science be taught in early childhood? J. Sci. Educ. Technol. 2005, 14, 315-336. [CrossRef]

40. Sakr, M. Digital Play in Early Childhood: What's the Problem? Sage: London, UK, 2019.

41. Arnott, L.; Kewalramani, S.; Gray, C.; Dardanou, M. Role-play and technologies in early childhood. In A Vygotskian Analysis of Children's Play Behaviours: Beyond the Home Corner; Kingdone, Z., Ed.; Routledge: Milton Park, UK, 2020; pp. 76-93.

42. Bird, J. "You need a phone and camera in your bag before you go out!": Children's play with imaginative technologies. Br. J. Educ. Technol. 2020, 51, 166-176. [CrossRef]

43. Craft, A. Childhood in a digital age: Creative challenges for educational futures. LRE 2012, 10, 173-190. [CrossRef]

44. Kalkusch, I.; Jaggy, A.-K.; Burkhardt Bossi, C.; Weiss, B.; Sticca, F.; Perren, S. Promoting Social Pretend Play in Preschool Age: Is Providing Roleplay Material Enough? Early Educ. Dev. 2020, 32, 1136-1152. [CrossRef]

45. Perren, S.; Sticca, F.; Weiss-Hanselmann, B.; Bossi, C.B. Let us play together! Can play tutoring stimulate children's social pretend play level? J. Early Child Res. 2019, 17, 205-219. [CrossRef]

46. Weisberg, D.S.; Hirsh-Pasek, K.; Golinkoff, R.M. Guided play: Where curricular goals meet a playful pedagogy. Mind Brain Educ. 2013, 7, 104-112. [CrossRef]

47. Fleer, M. Understanding the dialectical relations between everyday concepts and scientific concepts within play-based programs. Res. Sci. Educ. 2009, 39, 281-306. [CrossRef] 
48. Searle, K.A.; Litts, B.K.; Kafai, Y.B. Debugging open-ended designs: High school students' perceptions of failure and success in an electronic textiles design activity. Think. Skills Creat. 2018, 30, 125-134. [CrossRef]

49. Nikolopoulou, K.; Gialamas, V. ICT and play in preschool: Early childhood teachers' beliefs and confidence. Int. J. Early Years Educ. 2015, 23, 409-425. [CrossRef]

50. Bustamante, A.S.; Greenfield, D.B.; Nayfeld, I. Early childhood science and engineering: Engaging platforms for fostering domain-general learning skills. Sci. Educ. 2018, 8, 144. [CrossRef]

51. Alberola-Mulet, I.; Iglesias-Martínez, M.J.; Lozano-Cabezas, I. Teachers' Beliefs about the Role of Digital Educational Resources in Educational Practice: A Qualitative Study. Sci. Educ. 2021, 11, 239. [CrossRef]

52. Visković, I.; Sunko, E.; Mendeš, B. Children's Play-The Educator's Opinion. Sci. Educ. 2019, 9, 266. [CrossRef]

53. Kansteiner, K.; König, S. The Role(s) of Qualitative Content Analysis in Mixed Methods Research Designs. Forum Qual. Soz./Forum Qual. Soc. Res. 2020, 21, 1-22. [CrossRef]

54. Bildungsdepartement Kanton St. Gallen. Kanton St. Gallen Lehrplan Volksschule-Medien und Informatik: Einleitendes Kapitel [Canton St. Gallen Elementary School Curriculum-Media and Information Technology: Introductory Chapter]; Bildungsdepartement Kanton St. Gallen: St. Gallen, Switzerland, 2017.

55. Vogt, F.; Hollenstein, L.; Müller, K. Pretend Play Impulses and Videos. Available online: https://blogs.phsg.ch/weplaythefuture/ pretend-play-impulses-and-videos/ (accessed on 26 January 2022).

56. Kuckartz, U. Qualitative Inhaltsanalyse. Methoden, Praxis, Computerunterstützung; Beltz Juventa: Weinheim, Germany, 2019.

57. Onwuegbuzie, A.; Hitchcock, J. Advanced mixed analysis approaches. In Oxford Handbook of Multimethod and Mixedmethods Research Inquiry; Hesse-Biber, S., Burke Johnson, R., Eds.; Oxford University Press: New York, NY, USA, 2015; pp. $275-295$.

58. Brennan, R.L.; Prediger, D.J. Coefficient kappa: Some uses, misuses, and alternatives. Educ. Psychol. Meas 1981, 41, 687-699. [CrossRef]

59. Cohen, J. Statistical Power Analysis for the Behavioral Sciences, 2th ed.; Erlbaum Associates: Hillsdale, NJ, USA, 1923.

60. Arnott, L. Digital Technologies and Learning in the Early Years; Sage: London, UK, 2017. 